\title{
The inhibitory effects of soybean isoflavones on testicular cell apoptosis in mice with type 2 diabetes
}

\author{
ZHAOJIN DU ${ }^{1}$, ZHILEI QIU ${ }^{2}$, ZHANKUN WANG $^{3}$ and XINSHENG WANG ${ }^{4}$ \\ ${ }^{1}$ Reproductive Medical Center, Qingdao Women and Children's Hospital, Qingdao University, Qingdao, Shandong 266034; \\ ${ }^{2}$ Department of Urology, Qingdao Municipal Hospital, Qingdao, Shandong 266071; ${ }^{3}$ Department of Urology, \\ The Eighth People's Hospital of Qingdao, Qingdao, Shandong 266121; ${ }^{4}$ Department of Urology, \\ The Affiliated Hospital of Qingdao University, Qingdao, Shandong 266003, P.R. China
}

Received June 9, 2017; Accepted October 10, 2017

DOI: $10.3892 /$ etm.2017.5359

\begin{abstract}
The aim of the study was to investigate the inhibitory effects of soybean isoflavones (SI) on testicular cell apoptosis in mice with type-2 diabetes, as well as any possible mechanisms of action. Thirty male C57BL/6J mice were randomly divided into the control, diabetic (model), and treatment (SI) groups $(\mathrm{n}=10$ each). After treatment for 20 weeks, testicular cell apoptosis was detected and evaluated using DAPI staining. The expression and distribution of caspase-3 protein in testicular tissues was detected via immunohistochemistry, while caspase-3 mRNA expression was detected using RT-PCR. Bax and Bcl-2 protein expression was detected by western blot analysis. At week 20, DAPI staining showed that SI treatment significantly decreased testicular tissue cell apoptosis in diabetic mice. Immunohistochemical staining revealed that caspase- 3 expression in the SI group was significantly reduced relative to the model group. RT-PCR showed that SI treatment significantly decreased caspase-3 mRNA expression relative to the model group. Western blot analysis revealed that SI treatment significantly decreased Bax protein expression and increased $\mathrm{Bcl}-2$ protein expression $(\mathrm{P}<0.01)$. SI exhibited an inhibitory effect on testicular tissue cell apoptosis in mice with type 2 diabetes, with this effect possibly mediated by a decreased expression of caspase- 3 and Bax and increased Bcl-2 protein expression.
\end{abstract}

\section{Introduction}

The incidence of diabetes is currently very high and shows no decreasing trend. Complications from diabetes can seriously affect human health. Improvements in living standards

Correspondence to: Dr Xinsheng Wang, Department of Urology, The Affiliated Hospital of Qingdao University, 16 Jiangsu Road, Qingdao, Shandong 266003, P.R. China

E-mail: wangxs266003@163.com

Key words: soybean isoflavones, type 2 diabetes mellitus, mouse testicular cells, apoptosis and life expectancy have conversely increased the number of patients with diabetes. In China, the number of patients with diabetes account for $2.51 \%$ of the population, which indicates a 3-fold increase since 1980. Additionally, the number of patients with diabetes is on the increase (1). The testis is an extremely important part of the male reproductive organs and contains spermatogenic cells that can maintain the production of sperm cells. Damage to testicular cells can, not only cause a decline in male sexual function, but can also lead to infertility due to abnormal sperm production caused by testicular cell apoptosis (2). Previous findings showed that diabetes can cause erectile dysfunction, and its negative effect on erectile function is next only to senescence (3). Additionally, sexual dysfunction and testicular atrophy can be observed in $40-75 \%$ of patients with diabetes, and these patients usually also presented other complications such as spermatogenesis disorders (4). The incidence rates for these complications were much higher in patients with diabetes than those without, and these diseases may become more severe with aging and prolonged disease course (5-7). Therefore, the prevention and treatment of testicular disease caused by diabetes has become a focus for diabetes research.

Chinese medicine has been used in the treatment of diabetes for a long time. Many studies have shown that Chinese medicine can significantly improve the symptoms of diabetes and its related complications, and numerous studies on the pharmacological activities of Chinese medicines have also provided references for the use of Chinese medicine in the treatment of diabetes (8). Soybean isoflavones (SI), which are widely present in legume species, are a group of isoflavone estrogens. SI includes soy flavonoids, genistein, and legumin (9). It has been reported that SI exert a variety of pharmacological activities, including immunity building, anti-aging effects, anti-tumor effects, and other effects (10). In this study, SI was selected as an experimental drug and the aim was to investigate its inhibitory effects on testicular cell apoptosis in mice with type 2 diabetes.

\section{Materials and methods}

Materials and reagents. The following reagents were used in this study: SI and streptozotocin (STZ) (Sigma-Aldrich, 
St. Louis, MO, USA); Rabbit anti-mice caspase-3, Bax, and Bcl-2 primary polyclonal antibodies, and goat anti-rabbit HRP-labeled secondary polyclonal antibody (cat. no. 19677-0-AP, 23931-1-AP, 12789-1-AP; SA00001-2; Wuhan SanYing Biotechnology Co., Ltd., Wuhan, China); RNA extraction kit (Invitrogen Life Technologies, Carlsbad, CA, USA); primers, reverse transcription kit, and quantitative PCR kit (Takara, Dalian, China); BCA protein quantitation kit and cell lysates (Beyotime, Nantong, China); and immunohistochemical staining kit SP-9001 (Beijing Zhongshan Golden Bridge Biotechnology Co., Ltd., Beijing, China).

Experimental animals and grouping. Thirty specific pathogen-free (SPF) healthy C57BL/6J mice were randomly divided into three groups of 10 mice each: normal controls (control), diabetes (model) and SI-treated. STZ was dissolved in $0.1 \mathrm{~mol} / 1$ citrate buffer. After fasting for $24 \mathrm{~h}$, mice in the diabetes mellitus (DM) model group was administered STZ solution at a dose of $55 \mathrm{mg} / \mathrm{kg}$ via tail vein injection. All mice were kept in cages with controlled temperature $\left(22-24^{\circ} \mathrm{C}\right)$ and light cycles $\left(24^{\circ} \mathrm{C}\right.$ and $12 / 12$ light cycles). The humidity was $60 \pm 10 \%$ with free access to water. Citrate buffer solution was administered to mice in the control group. Venous blood was extracted from mice tail veins on day 3 post-injection to examine blood glucose levels, which were monitored for 5 days. A blood glucose level of $\geq 50 \mathrm{mg} / \mathrm{dl}$ indicated the successful establishment of the DM model. Mice with DM were used for subsequent experimentation. SI was dissolved in $0.5 \% \mathrm{CMC}-\mathrm{Na}$ after stirring for $2 \mathrm{~h}$ with a magnetic stirrer. The solution was kept overnight at room temperature and the supernatant was used. Intragastric administration of $300 \mathrm{mg} / \mathrm{kg} / \mathrm{d}$ SI solution to the SI group was performed at 8 a.m. daily, with $0.5 \%$ CMC-Na solution administered to mice in the control and model groups. Treatment persisted for 20 weeks, after which mice were anesthetized with ether and then immediately sacrificed by cervical dislocation. The bilateral testes were collected after laparotomy and the epididymis and excess adipose tissue were removed. One testis was numbered and fixed in freshly prepared $10 \%$ formalin solution for DAPI staining and immunohistochemical analysis. The other testis was placed in liquid nitrogen and stored in a refrigerator at $-80^{\circ} \mathrm{C}$ for mRNA and protein extraction. The study was approved by the Ethics Committee of Qingdao Women and Children's Hospital.

DAPI staining for detecting testicular cell apoptosis. After fixation, testicular tissue was paraffin-embedded and sectioned. After appropriate washing with PBS to remove the fixative solution, DAPI $(1 \mu \mathrm{g} / \mathrm{ml})$ staining was performed at room temperature in the dark for $5 \mathrm{~min}$. The DAPI staining solution was then removed via suction, the sections washed twice with PBS (5 min each), and staining was observed in the dark under fluorescence microscopy (Nikon, Tokyo, Japan).

Immunohistochemistry for detecting caspase-3 protein expression in testicular tissue. The procedure was performed as follows: Paraffin-embedded mouse testicular tissue sections were dewaxed and endogenous peroxidases were inactivated with $3 \% \mathrm{H}_{2} \mathrm{O}_{2}$. After antigen repair and serum blocking, the primary antibody (dilution, 1:500) was added and sections
Table I. Primer sequences used in RT-PCR.

\begin{tabular}{lll}
\hline Gene & Primer & Sequence \\
\hline Caspase-3 & F & 5'-AGAGAACAATGGCGGATA-3' \\
& $\mathrm{R}$ & 5'-CCAGTTGAGGGATGAAAG-3' \\
GAPDH & $\mathrm{F}$ & 5'-TGTGTCCGTCGTGGATCTGA-3' \\
& $\mathrm{R}$ & 5'-TTGCTGTTGAAGTCGCAGGAG-3' \\
\hline
\end{tabular}

were incubated overnight at $4^{\circ} \mathrm{C}$. After washing three times with PBS, secondary antibody (dilution, 1:1,000) was added and sections were incubated at room temperature for $30 \mathrm{~min}$. After washing three times with PBS again, DAB color development was performed. The slides were sealed with gum and observed under a microscope (TE2000-U; Nikon, Tokyo, Japan).

Representative regions were selected and staining results were evaluated according to the degree/intensity of staining and the percentage of positive cells. Regions were determined to exhibit no color, faint-yellow, brownish yellow, or dark brown, which were recorded as $0,1,2$ and 3 points, respectively. Under high-power magnification $(x 400)$, the percentage of positive cells was determined to be $<5,5-25,26-50 \%$, or $>50 \%$, which was recorded as $0,1,2$, and 3 points, respectively. The two scores were added, and a total score of $\geq 3$ points was recorded as a positive expression.

RT-PCR for detecting caspase-3 mRNA expression in testicular tissue. Approximately $50 \mathrm{mg}$ of testicular tissue for each mouse was taken from storage at $-80^{\circ} \mathrm{C}$. Total RNA was extracted and RNA concentration and purity were detected. Only samples with an A260/280 ratio between 1.8 and 2.0 were used. Reverse transcription was performed according to the manufacturer's instructions, and cDNA was subjected to RT-qPCR to detect caspase-3 mRNA expression. Primer sequences are listed in Table I. GAPDH expression was used as an endogenous control, and the reaction conditions were as: $94^{\circ} \mathrm{C}$ for $5 \mathrm{~min}$, followed by 30 cycles of $94^{\circ} \mathrm{C}$ for $30 \mathrm{sec}, 57^{\circ} \mathrm{C}$ for $30 \mathrm{sec}$ and $72^{\circ} \mathrm{C}$ for $30 \mathrm{sec}$, and finally $72^{\circ} \mathrm{C}$ for $5 \mathrm{~min}$. $\mathrm{Cq}$ values were processed using the $2^{-\Delta \Delta \mathrm{Cq}}$ method according to the following formula: $\Delta \mathrm{Cq}$ (target gene) $=\mathrm{Cq}$ (target gene) - Ct (control gene).

Western blot analysis. Testicular tissue from each mouse was taken and total protein was extracted. Protein concentration was measured and extracted protein samples were processed. Protein $(50 \mu \mathrm{g})$ from each sample was subjected to SDS-PAGE electrophoresis, followed by transfer to a PVDF membrane. After blocking with blocking solution at room temperature for $1 \mathrm{~h}$, the membranes were incubated with primary antibody (dilution, 1:1,000) overnight at $4^{\circ} \mathrm{C}$. After washing with TTBS, the membranes were incubated with secondary antibody (dilution, 1:2,000) at room temperature for $1 \mathrm{~h}$. After washing with TTBS, color development was performed with a color developer and images were obtained.

Statistical analysis. Data were presented as mean \pm standard deviation, and the data were processed with SPSS 17.0 soft- 
Control

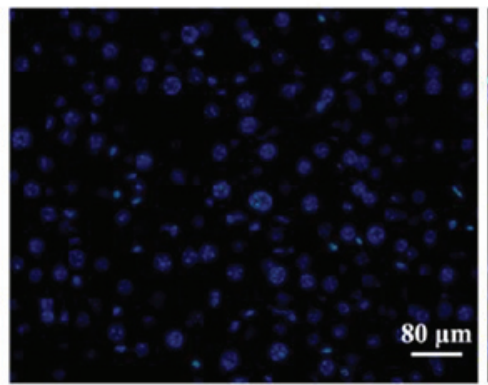

Model

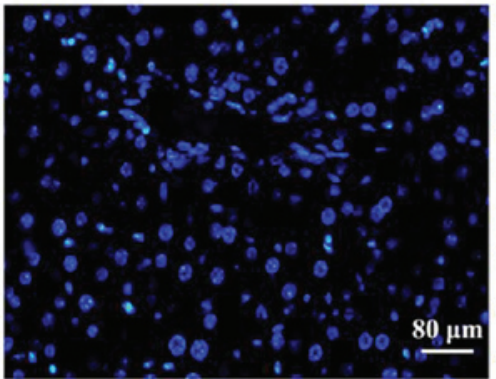

SI

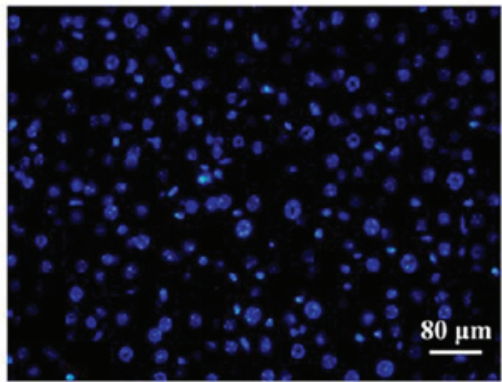

Figure 1. Effects of SI on testicular cell apoptosis in diabetic mice detected by DAPI staining. Testicular cells in the model group were deformed with condensed nuclei. The number of apoptotic cells in the SI group was significantly reduced.
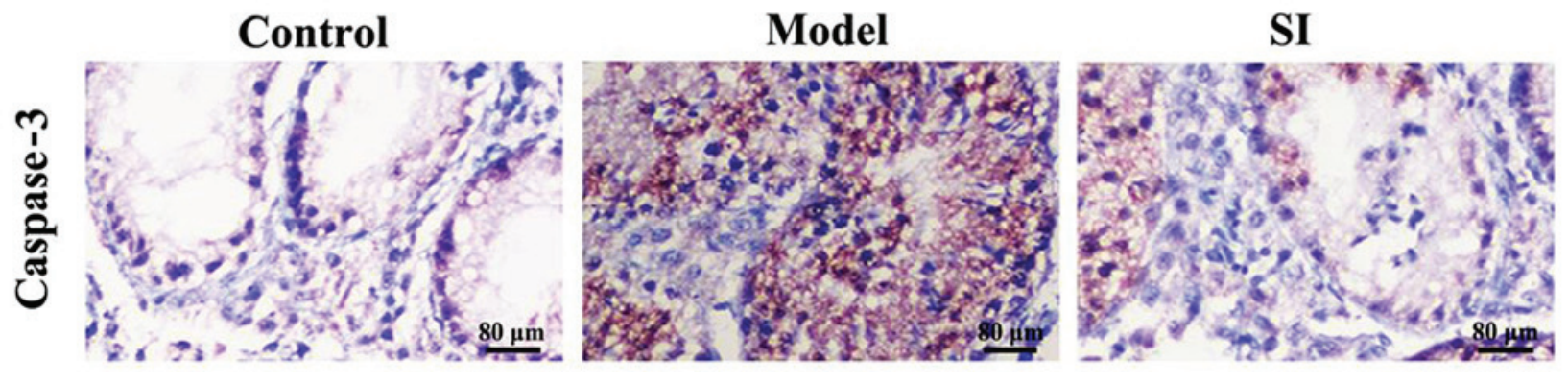

Figure 2. Immunohistochemical staining was used to detect SI effects on diabetic mouse testicular tissue caspase-3 expression. Positive caspase-3 immunohistochemical staining presented as a brownish yellow color. SI significantly reduced caspase-3 expression levels compared to the model group. SI, soybean isoflavones.

Table II. Caspase-3 protein expression in murine testicular tissue.

\begin{tabular}{lcccc}
\hline & & \multicolumn{3}{c}{ Caspase-3 } \\
\cline { 3 - 5 } Group & Cases & Positive cases & Positive rate (\%) & P-value \\
\hline Control & 10 & 1 & 10 & \\
Model & 10 & 9 & 90 & $<0.05$ \\
SI & 10 & 2 & 20 & \\
\hline
\end{tabular}

SI, soybean isoflavones.

ware (IBM Corporation, New York, NY, USA). Comparisons between the two groups were performed using paired t-tests. Comparisons of countable data between the groups were performed using $\chi^{2}$ tests. $\mathrm{P}<0.05$ was considered statistically significant.

\section{Results}

Effects of SI on testicular cell apoptosis in diabetic mice. DAPI staining results showed that the testicular cells in the model group were deformed, with condensed, brightly stained nuclei. Cell status in the SI group was significantly improved and the number of apoptotic cells was significantly reduced (Fig. 1).
Effects of SI on diabetic mouse testicular tissue caspase-3 expression. Positive caspase- 3 immunohistochemical staining was indicated by the presence of a brownish yellow color. Caspase-3 protein was found mainly located in the cytoplasm and showed diffused or scattered distribution patterns (Fig. 2). The positive caspase- 3 expression rate in the control, model, and SI groups was 10,90 , and $20 \%$, respectively (Table II). SI significantly reduced caspase- 3 expression relative to the model group.

Effects of SI on caspase-3 mRNA expression in diabetic mouse testicular tissue. Compared with the control group, caspase-3 mRNA expression in the model and SI groups were significantly increased $(\mathrm{P}<0.01$ or $\mathrm{P}<0.05)$. Caspase- 3 mRNA expression in the SI group was significantly decreased relative to the model group $(\mathrm{P}<0.05)$ (Fig. 3).

Effects of SI on Bax and Bcl-2 protein expression in diabetic murine testicular tissue. Bcl-2 protein expression was significantly decreased $(\mathrm{P}<0.01)$ and Bax protein expression was significantly increased $(\mathrm{P}<0.01)$ in the model and SI groups relative to the control group. Bcl-2 protein expression was significantly increased $(\mathrm{P}<0.01)$ and Bax protein expression was significantly decreased $(\mathrm{P}<0.01)$ in the $\mathrm{SI}$ group relative to the model group (Fig. 4).

\section{Discussion}

In recent years, with the increasing number and progressively younger profile of diabetes patients, the effect of diabetes on 


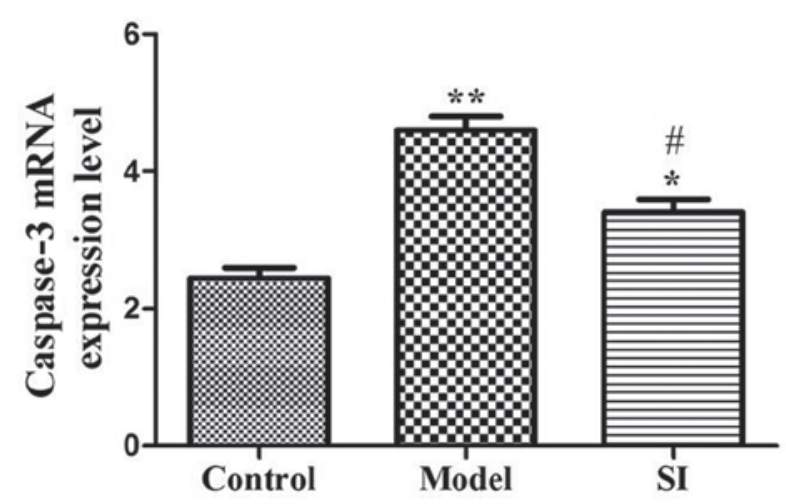

Figure 3. Effects of SI on Caspase-3 mRNA expression in diabetic mouse testicular tissue. RT-qPCR results showed that caspase- 3 mRNA expression was significantly higher in the model and SI groups relative to the control group. Caspase-3 mRNA expression in the SI group was significantly decreased relative to the model group. ${ }^{* *}$ Compared with the control group, $\mathrm{P}<0.01$; "compared with the control group, $\mathrm{P}<0.05$; " compared with the SI group, $\mathrm{P}<0.05$. SI, soybean isoflavones.

the reproductive system has attracted increased attention. The testes are extremely important parts of the male reproductive organs. Spermatogenic cells in the testis can maintain sperm cell production. When testicular cells are damaged, cell apoptosis results, leading to the production of abnormal sperm or even infertility (11). Diabetes can, not only lead to the attenuation of spermatogenic cell function, but also to testicular cell apoptosis (12). Although the mechanism, progression, and treatment of diabetes have been extensively investigated (13), cell apoptosis caused by testicular tissue lesions (a complication of diabetes) is under investigation, and cannot be effectively corrected with current available treatments.

Caspase plays an essential role in a variety of cell apoptotic processes. Previous findings have shown that the caspase- 3 protease plays a key role in apoptosis (14). In apoptotic pathways, a part or all of the caspase- 3 protein can be utilized to hydrolyze protein substrates. In addition, caspase- 3 can also activate other caspase proteins. Previous studies have demonstrated that caspase-3 inhibition through specific protease inhibitors can significantly inhibit cell apoptosis (15). Bcl-2, which plays an important role in apoptosis, has an inhibitory effect on cell apoptosis (16). Bcl-2 can protect cells from multiple forms of death and increase cell survival, resulting in an increase in the number of cells. In some tumor cells, upregulated Bcl-2 expression can protect tumor cells from death or at least increase their life span (17), indicating that the Bcl-2 gene is closely correlated with tumor progression. In contrast to the $\mathrm{Bcl}-2$ gene, the Bax gene can promote apoptosis (18). Bax belongs to the same family as the Bcl-2 gene, but has the opposite function, and the equilibrium state of those two determines the degree of cell apoptosis. As a homologous dimer, Bcl-2 can inhibit cell apoptosis. When Bax protein levels are increased and Bax protein dimerizes with Bcl-2 or if Bax is present as a homologous dimer, cell apoptosis is increased (19).

This study aimed to investigate the inhibitory effect of SI on testicular cell apoptosis in mice with type 2 diabetes, as well as the possible mechanism of action. DAPI staining was used to detect the mouse testicular cell apoptosis, and the results
A
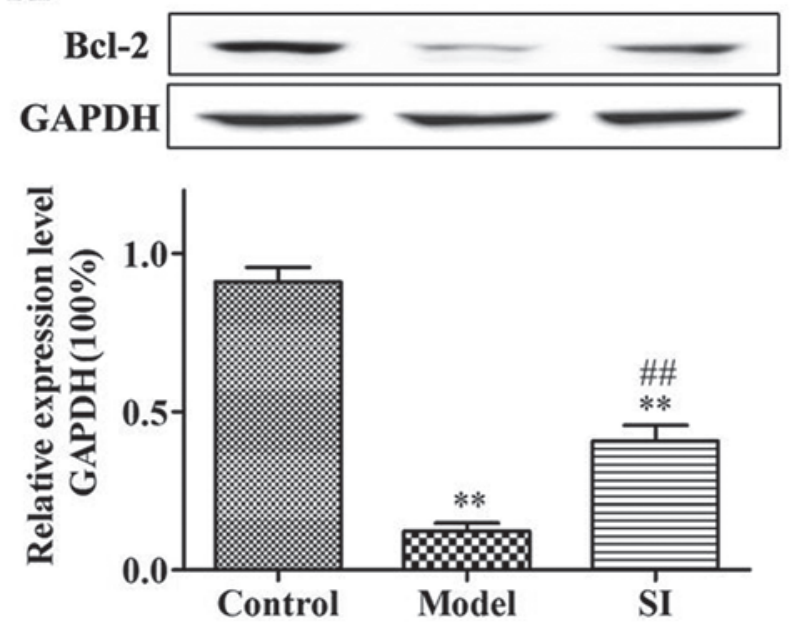

B
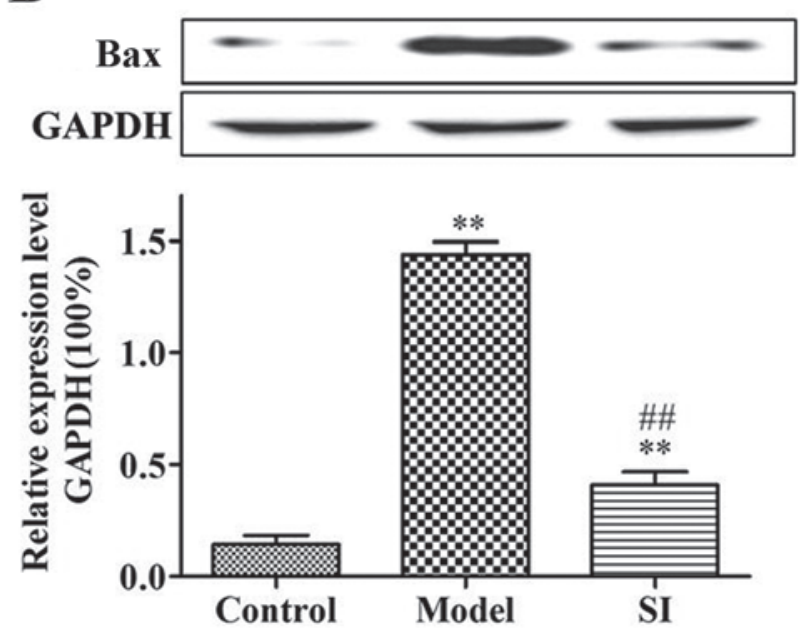

Figure 4. Western blot detection of diabetic mouse testicular tissue Bax and Bcl-2 protein expression. (A) Bcl-2 protein expression. Bcl-2 protein levels were significantly decreased in the model and SI groups relative to the control group. Bcl-2 protein expression was significantly increased in the SI group relative to the model group. (B) Bax protein expression. Bax protein levels were significantly increased in the model and SI groups relative to the control group. Bcl-2 protein expression was significantly decreased in the SI group relative to the model group. ${ }^{* *}$ Compared with the control group, $\mathrm{P}<0.01 ;{ }^{\# \#}$ compared with the model group, $\mathrm{P}<0.01$. SI, soybean isoflavones.

showed that SI significantly reduced testicular apoptosis. The expression and distribution of caspase- 3 in mouse testicular tissue was detected by immunohistochemistry, and caspase- 3 mRNA expression levels were detected using RT-PCR. The two methods indicated that SI significantly decreased caspase-3 expression. Previous findings have shown that the downregulation of caspase- 3 expression reduced testicular spermatogenic cell apoptosis in rats with varicocele (20). Bax and Bcl-2 protein expression levels were detected using western blot analysis, and the results showed that SI significantly decreased Bax protein expression levels and increased Bcl-2 protein levels. A similar study showed that Bcl-2 protein expression level was directly associated with murine spermatogenic cell apoptosis (21). Tapanainen et al (22) established a mouse model of cell apoptosis in the reproductive duct, and found 
that Bax protein expression was significantly increased and Bcl-2 protein expression was significantly decreased during cell apoptosis.

In conclusion, SI has an inhibitory effect on testicular cell apoptosis in mice with type 2 diabetes, and this effect may be achieved by decreased expression of caspase- 3 and Bax and increased expression of Bcl-2 protein.

\section{References}

1. Funatsu H, Yamashita H, Nakamura S, Mimura T, Eguchi S, Noma $\mathrm{H}$ and Hori S: Vitreous levels of pigment epitheliumderived factor and vascular endothelial growth factor are related to diabetic macular edema. Ophthalmology 113: 294-301, 2006.

2. Zhang GP, Han D, Liu G, Gao SG, Cai XQ, Duan RH and Feng XS: Effects of soy isoflavone and endogenous oestrogen on breast cancer in MMTV-erbB2 transgenic mice. J Int Med Res 40: 2073-2082, 2012.

3. Gautam AK, Agarwal K, Shah BA, Kumar S and Saiyed HN: Lead induced spermatoxicity in mouse and MPG treatment. J Environ Biol 22: 287-291, 2001.

4. Montorsi F, Adaikan G, Becher E, Giuliano F, Khoury S, Lue TF, Sharlip I, Althof SE, Andersson KE, Brock G, et al: Summary of the recommendations on sexual dysfunctions in men. J Sex Med 7: 3572-3588, 2010.

5. Maiorino MI, Bellastella G and Esposito K: Diabetes and sexual dysfunction: Current perspectives. Diabetes Metab Syndr Obes 7: 95-105, 2014.

6. Tamler R: Diabetes, obesity, and erectile dysfunction. Gend Med 6: 4-16, 2009.

7. Thorve VS, Kshirsagar AD, Vyawahare NS, Joshi VS, Ingale KG and Mohite RJ: Diabetes-induced erectile dysfunction: Epidemiology, pathophysiology and management. J Diabetes Complications 25: 129-136, 2011.

8. Zhang TT and Jiang JG: Active ingredients of traditional Chinese medicine in the treatment of diabetes and diabetic complications. Expert Opin Investig Drugs 21: 1625-1642, 2012.

9. Kevin L: Erectile dysfunction and testosterone deficiency as gender-specific markers of cardiometabolic risk in minority and non-minority men: Potential role of social determinants. Men's Health 9: 139-145, 2012.

10. Junuzovic D, Hasanbegovic M and Masic I: Risk factors for erectile dysfunction in patients with newly diagnosed diabetes mellitus. Med Arh 64: 345-347, 2010.
11. Bukovsky A: Novel methods of treating ovarian infertility in older and POF women, testicular infertility, and other human functional diseases. Reprod Biol Endocrinol 13: 10, 2015.

12. Dhindsa S, Prabhakar S, Sethi M, Bandyopadhyay A, Chaudhuri A and Dandona P: Frequent occurrence of hypogonadotropic hypogonadism in type 2 diabetes. J Clin Endocrinol Metab 89: 5462-5468, 2004.

13. Pitteloud N, Hardin M, Dwyer AA, Valassi E, Yialamas M, Elahi D and Hayes FJ: Increasing insulin resistance is associated with a decrease in Leydig cell testosterone secretion in men. J Clin Endocrinol Metab 90: 2636-2641, 2005.

14. Cregan SP, Dawson VL and Slack RS: Role of AIF in caspasedependent and caspase-independent cell death. Oncogene 23: 2785-2796, 2004.

15. Hayashi K, Kojima R and Ito M: Strain differences in the diabetogenic activity of streptozotocin in mice. Biol Pharm Bull 29: 1110-1119, 2006

16. Cory S, Huang DCS and Adams JM: The Bcl-2 family: Roles in cell survival and oncogenesis. Oncogene 22: 8590-8607, 2003.

17. Song W, Liu MG, Zhang JB, Zhang JJ, Sun MM and Yu QK: Mechanism of action of EBV, Bcl-2, p53, c-Myc and Rb in non-Hodgkin's lymphoma. Eur Rev Med Pharmacol Sci 20: 1093-1097, 2016.

18. Brady HJ and Gil-Gómez G: Bax. The pro-apoptotic Bcl-2 family member, Bax. Int J Biochem Cell Biol 30: 647-650, 1998.

19. Lu QL, Abel P, Foster CS and Lalani EN: bcl-2: Role in epithelial differentiation and oncogenesis. Hum Pathol 27: 102-110, 1996.

20. Sinha Hikim AP, Lue Y, Diaz-Romero M, Yen PH, Wang C and Swerdloff RS: Deciphering the pathways of germ cell apoptosis in the testis. J Steroid Biochem Mol Biol 85: 175-182, 2003.

21. Furuchi T, Masuko K, Nishimune Y, Obinata M and Matsui Y: Inhibition of testicular germ cell apoptosis and differentiation in mice misexpressing Bcl-2 in spermatogonia. Development 122: 1703-1709, 1996.

22. Tapanainen JS, Tilly JL, Vihko KK and Hsueh AJ: Hormonal control of apoptotic cell death in the testis: Gonadotropins and androgens as testicular cell survival factors. Mol Endocrinol 7: 643-650, 1993.

This work is licensed under a Creative Commons Attribution-NonCommercial-NoDerivatives 4.0 International (CC BY-NC-ND 4.0) License. 